\title{
Drop-Burst Length Evaluation of Urban VANETs
}

\author{
Awos Kh. Ali, Iain Phillips, and Huanjia Yang
}

\begin{abstract}
Networks performance is traditionally evaluated using packet delivery ratio (PDR) and latency (delay). We propose an addition mechanism the drop-burst length (DBL). Many traffic classes display varying application-level performance according to the pattern of drops, even if the PDR is similar. In this paper we study a number of VANET scenarios and evaluate them with these three metrics.

Vehicular Ad-hoc Networks (VANETs) are an emerging class of Mobile Ad-hoc Network (MANETs) where nodes include both moving vehicles and fixed infrastructure. VANETs aim to make transportation systems more intelligent by sharing information to improve safety and comfort. Efficient and adaptive routing protocols are essential for achieving reliable and scalable network performance. However, routing in VANETs is challenging due to the frequent, high-speed movement of vehicles, which results in frequent network topology changes.

Our simulations are carried out using NS2 (for network traffic) and SUMO (for vehicular movement) simulators, with scenarios configured to reflect real-world conditions. The results show that OLSR is able to achieve a best DBL performance and demonstrates higher PDR performance comparing to AODV and GPSR under low network load. However, with GPSR, the network shows more stable PDR under medium and high network load. In term of delay OLSR is outperformed by GPSR.
\end{abstract}

\section{Keywords-VANETs, Routing, AODV, OLSR, GPSR.}

\section{INTRODUCTION}

In the last few years, VANETs have become an key research topic due to increasing demand for technology to make roads safer and manage traffic, alongside the possibilities for in-car entertainment and communication. VANETs represent a class of Mobile ad hoc networks (MANETs) where nodes (vehicles) rapidly come in and out of communication range of each other. Vehicles in VANETs act as routers, sending, receiving and forwarding packets between each other. VANETs allow for the provision of Intelligent Transportation Systems (ITS) that help avoid congestion on and to provide safer roads. Vehicles establish wireless communication with other vehicles (V2V) and with fixed Road Side Units (RSUs) (V2I). RSUs take part in both the wireless and wired networks and provide connectivity to the Internet [1]. Network topology in VANETs changes frequently, but the changes are sometimes predictable with vehicle velocity and position partly constrained by roads, traffic congestion, driver behaviour and traffic signals. The challenges for urban VANETs also include signal interference and blocking by buildings. As communication links exist between vehicles for only short-lived times, this affects the performance of VANET applications. This is the subject of our study.

Manuscript received November 11, 2016, revised May 16, 2017.

Awos Kh. Ali and Iain Phillips are with the Computer Science at University of Loughborough, UK, e-mail: a.k.ali@lboro.ac.uk.

Huanjia Yang is with IBM Client Innovation Centre in Leicester, UK
VANET performance is partly governed by the routing protocol that determines how packets are forwarded from node to node. VANETs usually employ traditional MANET routing protocols such as Optimized Link State Routing protocol (OLSR), Ad hoc on Demand Distance Vector Routing (AODV) and Greedy Perimeter Stateless Routing (GPSR). These protocols belong to three different classes (reactive, proactive and position-aware) and they perform well in multi-hop wireless ad-hoc networks. However, the rapid network topology change and the affects of signal attenuation means that established paths do not stay valid for long and the recomputation of the path affects the application traffic performance.

In this paper we evaluate three different routing protocols (OLSR, GPSR, AODV) in a VANET urban environment. We measure the performance of the protocols through the perceived performance of the applications being delivered by the network. Packets are usually dropped in groups rather than randomly distributed through time. This means that, as well as the traditional metrics of delay and packet delivery ratio (PDR), we examine the distribution of the lengths of the group drops, which we refer to as Drop Burst Length (DBL). This provides with a richer indication as to the effects of performance the QoS of real-time traffic, which traditionally is adaptive to single packet errors, but less so to burst drops.

\section{BACKGROUND AND RELATED WORK}

Routing protocols in VANET are categorised into two main classes of position-based and topology-based protocols. A separate classification is into reactive (on-demand) and proactive (table-driven). Topology-based protocols use link state information in the network to deliver packets to their destinations. While position based protocols utilise geographical position of the intermediate nodes[2]. In reactive routing protocols (e.g. AODV[3]), a path is established when it is needed. This allows nodes to communicate with each other and maintain routes in use. This reduces the amount of network overhead that caused by broadcasting routing information. The proactive technique (e.g. OLSR [4]) determines routes to all nodes in the network in advance by store these routes in one or several routing tables, hence, routes to all nodes always available whenever they needed. Nodes in a topology based update their routing tables periodically in order to discover all routes by exchanging routing messages. As a result, the route update process causes large network overhead. Furthermore, as nodes move the link-state information between nodes will change, which itself leads to the overhead of reconvergance and also to lost packets while reconvergance takes place.

Position-based routing protocols (e.g. GPSR[5]) utilise geographical information for each node in topology to make all routing decisions, thus, each node needs to announce its 


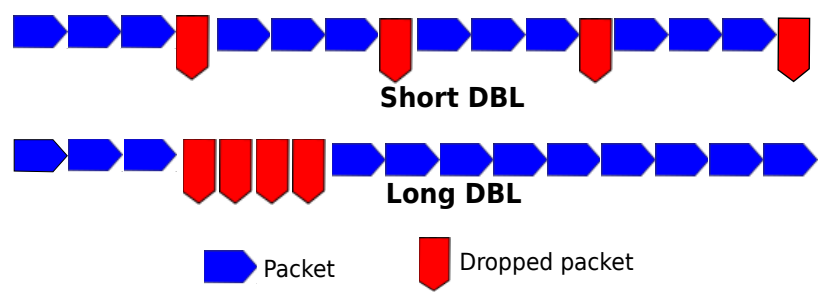

Fig. 1. Short and long DBL

position, to do that, each node periodically broadcast small packets called beacons contain geographical information of the node. As with other routing protocols increased node velocity leads to inaccurate position information and highly dynamic topology leads to route disconnect, where the network is unable to forward packets, leading to loss.

Furthermore, for all networks the density of the nodes, i.e. the distribution of the node distances affects performance. Protocols will fail in sparse networks due to some regions without nodes (voids).

For simulation to be effective to evaluate the performance of a network it must be configured to be representative of reality. Factors that increase simulation realism in the case of VANETs are the application network traffic model, the mobility model (vehicle traffic model), the medium access (MAC) protocols and the model of the impact of an urban area obstacles on radio signals together with fading of the radio channel. One or more of these is often neglected, consequently, results are less likely to be truly representative.

Rani et al. [6] used only V2V network topology. While Zuo [7]used a heterogeneous network model, proposing the vehicle node density parameter to improve the performance of the AODV routing protocol and OLSR routing protocol under two different scenarios; however, they do so in the absence of a realistic MAC protocol and fading propagation model for their environment, $802.11 \mathrm{~g}$ standard was configured and $1440 \mathrm{~B}$ as a packet payload. Khan [8] employed various numbers of nodes up to 120 nodes moving within the real map of US Census Bureau, they consider a realistic fading model that reflects the impact of obstacles on radio signal and IEEE 802.11p was configured. However, only light network load has been taken into account and the network traffic was picked up randomly and do not represent a VANET application. Similar works also neglect the affects of representative network traffic [9], [10]. Furthermore, the authors in [11] present the performance evaluation of AODV, OLSR and DYMO routing protocols, they configured Two Ray Ground as a propagation model, which is a simple propagation model and do not reflect the impact of an urban environment on wireless signal. A paper by Haerri et al. [12] emphasis on artificial mobility map only and they miss many factors that they have a direct influence on the network performance such as propagation model and VANET application traffic.

Moreover, the majority of the previously mentioned evaluation studies used traditional metrics to measure network performance with different routing protocols such as average endto-end delay and average packet loss. While there instances where these have some value, e.g. a safety critical message must be delivered within a short delay, these metrics do not fully reflect actual network performance as perceived by the application and user; they measure averages sometimes losing vital information in the calculation.To overcome these issues, we have introduced Drop Burst Length (DBL). This measures the probability of drop a consecutive number of packets in each connection. Real time traffic is more susceptible to burst drops so this metric provides a better indication of performance. Fig. 11illustrates short and long DBL and how it has an impact on application performance.

This paper is an extension of our previous work [13] were three routing protocols were selected as a representative of reactive, proactive and geographically-based routing, AODV, OLSR and GPSR respectively, and evaluated through simulation. Our work considers these protocols in a realistic urban environment with two mobility models: an artificial map (Manhattan map) and two real world maps (part of the London congestion zone and part of the Leicester city centre).

\section{Simulation SETUP}

To ensure some realism in our simulation we consider the following factors:

a) The network traffic model: According to U.S. Department of Transportation report [14], the shape of the network traffic depends on an application requirements, different VANET applications create different network traffic. VANET applications can be categorised into three major classes (Safety applications, traffic management applications and commercial applications). Table I] presents typical application requirements. Each category has a set of requirements to perform efficiently, safety-critical class for example, it required a minimum 10 messages to be sent every second with small packet size using connection-less transport protocol, and to be delivered within $100 \mathrm{~ms}$. In this paper, we employ between $5 \mathrm{~s}-$ $20 \mathrm{~s}$ flows of 10 packets per second. Each simulation is for a random length of time with the total number of flows varying from 200 (low) to 1000 (high).

b) The communication model: we employ $801.11 \mathrm{p}$ as the MAC layer.

c) Network device topology: We consider each vehicle to be part of the network and for there to be a set of fixed wireless roadside units also forwarding traffic.

d) The vehicle traffic model: Several mobility models are proposed to simulate VANET urban environment. Most of evaluation studies used even an artificial mobility model or digital maps of an urban area. In order to observe routing protocols behaviour more in-depth, both models are involved as follow.

- Real street map: in this paper part of real map of the London congestion zone and Leicester city centre are used to generate random vehicle trips. The Openstreetmap website enables to capture a real world map in different format, so it is used to capture part of the London congestion zone map and Leicester city centre. In order to generate random trips on the captured map, Simulation of Urban MObility (SUMO) framework [15] is involved. 


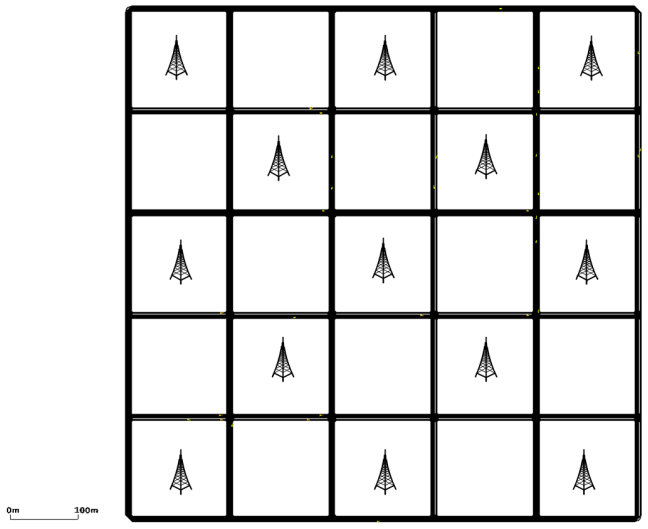

Fig. 2. Manhattan mobility model map with RSUs in SUMO.

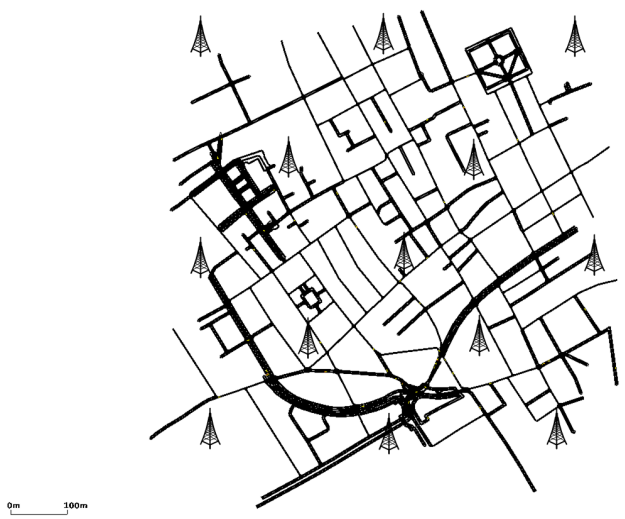

Fig. 3. Part of the London congestion zone with RSUs in SUMO.

It is an open source traffic simulation package developed by the German Aerospace Centre (DLR) in 2001.

- Manhattan mobility model: This model considered as one of the most popular mobility models that represents an urban environments because it contains a grid of streets that organised vertically and horizontally. In the Manhattan model, nodes follow a probabilistic approach in the selection of its direction, since at each intersection a vehicle chooses to keep moving in the same direction

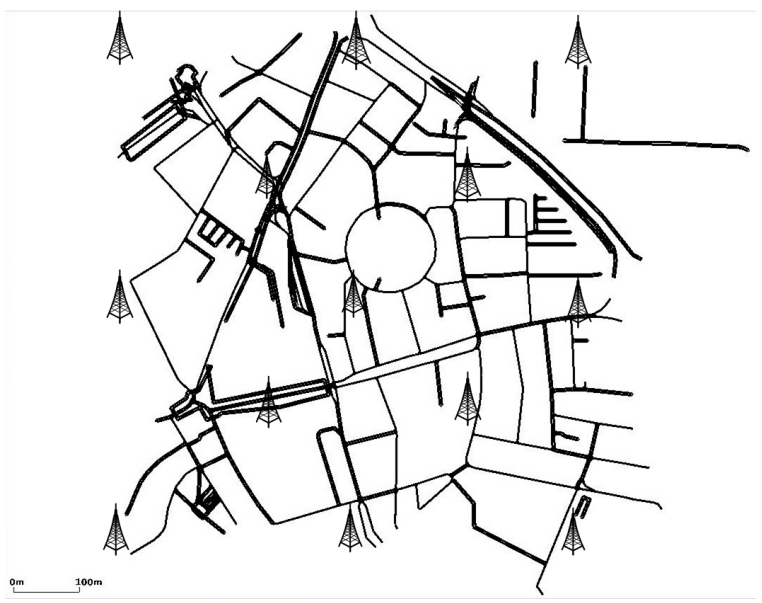

Fig. 4. Part of the Leicester city centre with RSUs in SUMO.
TABLE I

SOME EXAMPLES OF VANET APPLICATIONS REQUIREMENTS 14 [SC=S AFTEY CRITICAL, CRS=COOPERATIVE ROAD SAFETY, TM=TRAFFIC MANAGEMENT, CM=COMMERCIAL,

$\mathrm{CO}=$ CONNECTION-ORIENTED, $\mathrm{CL}=$ CONNECTION-LESS, LW $=$ LIGHTWEIGHT,HW=HEAVY-WEIGHT(IP)], V2X=V2V OR V2I

\begin{tabular}{|c|c|c|c|c|c|c|}
\hline Application & $\begin{array}{l}\text { Cate- } \\
\text { gory }\end{array}$ & $\begin{array}{l}\text { Conn. } \\
\text { mode }\end{array}$ & $\begin{array}{r}\text { Allowable } \\
\text { latency } \\
(\mathrm{ms})\end{array}$ & $\begin{array}{r}\text { Minimum } \\
\text { message freq. } \\
(\mathrm{Hz})\end{array}$ & $\begin{array}{r}\text { Transport } \\
\text { protocol }\end{array}$ & $\begin{array}{l}\text { Packet } \\
\text { Format }\end{array}$ \\
\hline Braking Warning & $\mathrm{SC}$ & $\mathrm{V} 2 \mathrm{X}$ & 100 & 10 & CL & LW \\
\hline $\begin{array}{l}\text { Emergency } \\
\text { vehicle warning }\end{array}$ & $\mathrm{SC}$ & $\mathrm{V} 2 \mathrm{X}$ & 100 & 10 & CL & LW \\
\hline $\begin{array}{l}\text { Roadwork } \\
\text { warning }\end{array}$ & CRS & $\mathrm{I} 2 \mathrm{~V}$ & 100 & 2 & CL & LW \\
\hline Weather condition & CRS & $\mathrm{V} 2 \mathrm{~V}$ & 500 & 2 & $\mathrm{CO}$ & HW \\
\hline $\begin{array}{l}\text { Intersection } \\
\text { management }\end{array}$ & $\mathrm{TM}$ & $\mathrm{I} 2 \mathrm{~V}$ & 500 & 2 & $\mathrm{CL}$ & LW \\
\hline $\begin{array}{l}\text { Time to traffic } \\
\text { light change }\end{array}$ & $\mathrm{TM}$ & $\mathrm{I} 2 \mathrm{~V}$ & 100 & $1-10$ & CL & LW \\
\hline $\begin{array}{l}\text { Electronic } \\
\text { commerce }\end{array}$ & $\mathrm{CM}$ & $\mathrm{I} 2 \mathrm{~V}$ & 500 & 1 & $\mathrm{CO}$ & HW \\
\hline $\begin{array}{l}\text { Media } \\
\text { downloading }\end{array}$ & $\mathrm{CM}$ & $\mathrm{I} 2 \mathrm{~V}$ & 500 & 1 & $\mathrm{CO}$ & HW \\
\hline
\end{tabular}

or change it. The probability of going straight is 0.5 and taking a left or right is 0.25 . It can be noted that this model is not suitable for highway systems [16].

Fig. 2, 3 and 4 illustrate simulation scenarios in a configured Manhattan map, portion of the London congestion zone and portion of the Leicester city centre respectively using SUMO. 100 vehicles move at speeds up to $20 \mathrm{~m} / \mathrm{s}$, with 13 fixed roadside units.

e) Propagation model: In an urban environment, radio frequency (RF) suffers from severe fading due to the presence of buildings or other obstacles, these act as barriers for radio signals. Consequently, it is unlikely that line of sight between transmitter and receiver exists. In order to reflect the characteristic of an urban environment, the Nakagami model is used in this paper. This propagation model is a mathematical modelling of a radio channel with fading. It represents a close characteristic of the real world wireless communication channel, because it has more configurable parameters compared with other propagation models such as two-ray ground and shadowing. The Nakagami propagation model has the ability of simulate various levels of fading in a wireless channel, from a free space channel to severe attenuation channel in urban environments by changing shaping factor values[17] [18]. In this paper, we employ the Nakagami propagation using parameters $\left(m_{0}, m_{1}, m_{2}=1.0\right.$, use_nakagami_dist_ $=$ false, $\gamma_{0}, \gamma_{1}, \gamma_{2}=2.0$ and $d_{0 \gamma}, d_{1 \gamma}=200,500$ respectively) [17].

\section{RESULTS AND DISCUSSION}

We analyse network performance using DBL, PDR, C2C delay as described in earlier. Simulations were undertaken with increasing load, i.e. numbers of traffic flows (connections). Each flow has random duration ( $5 \mathrm{~s}$ to $20 \mathrm{~s}$ ) at 10pps, on each map. Each run was performed five times with the same random source and destination selections for each flow on each run. 

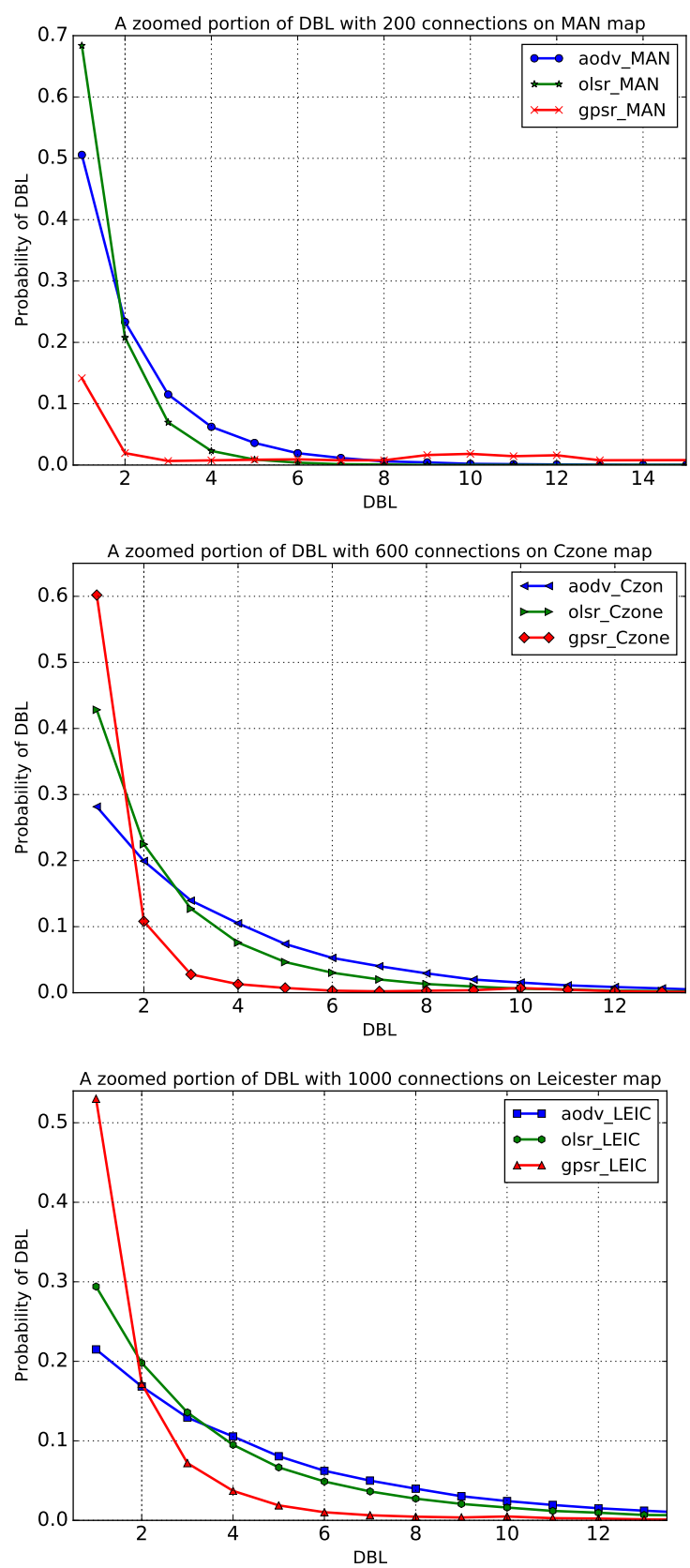

Fig. 5. Short Drop Burst of AODV, OLSR and GPSR with various number of connections (A zoomed portion).

Fig. 5 and 6 show the DBL for three loads. We observe the performance of the selected routing protocols (AODV, OLSR and GPSR) is similar on the all maps.

Each protocol shows different performance:

- GPSR achieves the shortest C2C delay because it considers the closest neighbour that has a route to destination. Fig. 8 illustrates this delay in low, medium and high loads.

- Fig. 8 also shows that with AODV packets take longer to be delivered under different network load on all maps. These longer delays are due to its route initialisation mechanism, it takes time to set-up a route to destination (sending a RREQ and waiting for a RREP). This leads to packets being queued and dropped before transmission and the probability of dropping consecutive packets with AODV increases along the simulation.

- OLSR provides a route to a destination immediately, and source node with GPSR already has the closest neighbour that has a route to destination, this can give an advantage for those protocols over AODV in terms of delay and DBL (Fig. 5 \& 6), especially at the start of the connection.

- Using DBL we observe that long packet burst drops are avoided (Fig. 6). OLSR and AODV recover a broken route quickly when a failure is detected, despite the fact that they have higher probability of one packet DBL under low network among other protocols see Fig. 5

- GPSR shows a worse performance in term of DBL. The probability of dropping the entire flow is much higher compared with AODV and OLSR, see Fig. 6, although it performs much better under low network.

- OLSR outperforms AODV and GPSR in terms of DBL and PDR under low, medium and high network load. However, as load increases, the performance reduces as the drop ratio on MAC layer increases

- With AODV, the poor performance of the network is due to unavailability of routes to the next hop (NR), so the drop ratio increases at the network (routing) layer as shown in the Table III AODV failed to calculate paths from source to destination under high network load as a consequence of incapability of handling the growth in routes demanding.

- The reason behind of the most dropped packets with OLSR is MAC getting busy due to the frequent updates of OLSR routing tables. As network load increases OLSR failed to provide paths towards destinations.

- Despite the weakness with GPSR performance in terms of PDR under low network load, it shows a better performance under medium and high load (Fig. 7).

\section{CONCLUSION}

Our results indicate that the variation of the selected urban maps configured Manhattan map, the London congestion zone and Leicester city centre maps have little influence the performance network traffic for these simulations.

Using our performance metric (DBL) we find OLSR outperforms AODV and GPSR. With OLSR packet drops more commonly due to a busy MAC layer with AODV the failure to establish a path to the destination. With GPSR the network experiences a stable performance and the delay is the shortest among other protocols.

While no protocols provide all the requirements of a safety critical system, this led us to address key required to design a new routing algorithm that has the capability to cope with VANET characteristics. These key findings are as following:

- Route set-up time has a crucial influence on network performance especially when the connection time is short.

- Geographic location information could be utilised to reduce packets delivery time, nevertheless, this could lead to frequent route disconnection due to a rapid topology change. 

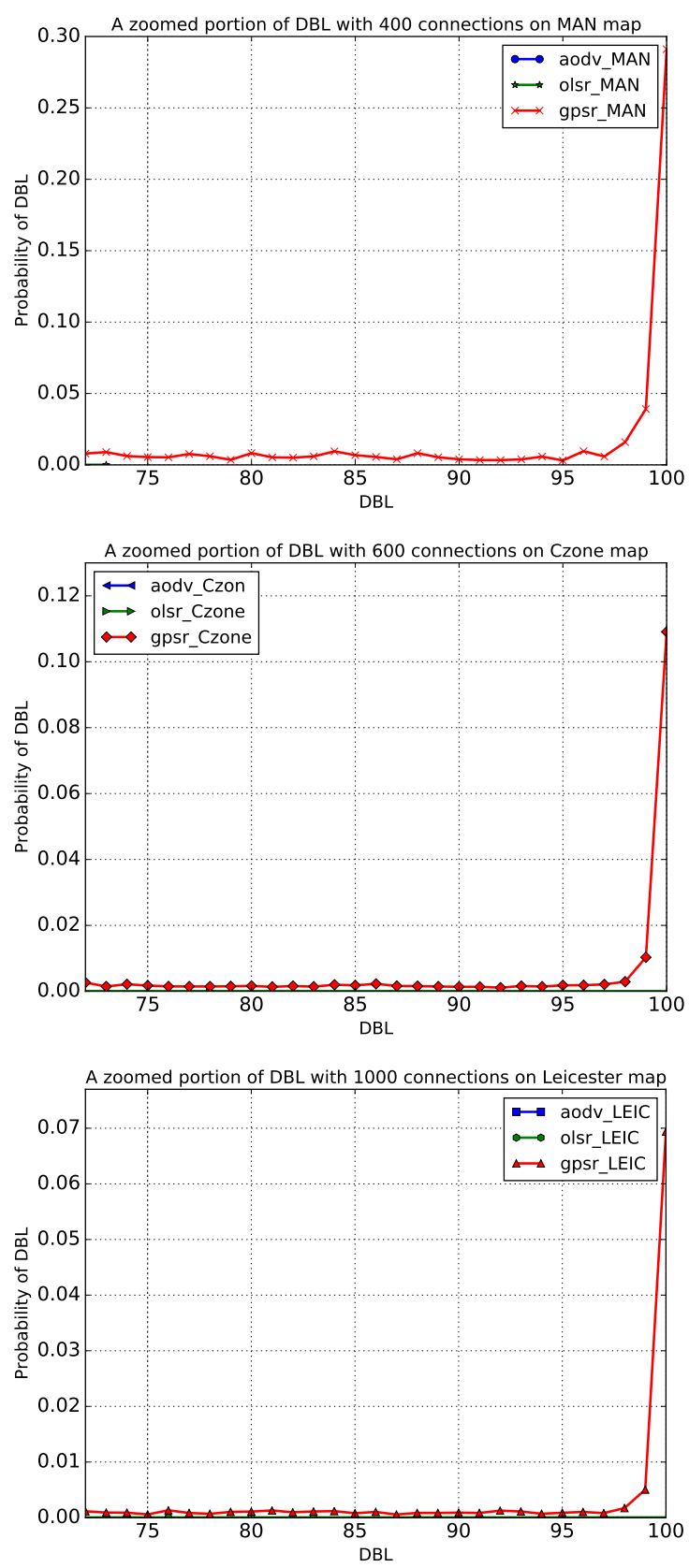

Fig. 6. Long Drop Burst of AODV, OLSR and GPSR with various number of connections (A zoomed portion).

- Unicast routing fulfils some VANET applications requirements, however, it is not sufficient to satisfy all the applications.

- The choice of routing protocol has an effect on DBL, this could have an impact on applications performance, especially real-time applications.

Future work will involve improving the framework for testing by employing more realistic simulated application traffic. This will then provide a platform to investigate new routing protocols to act as an alternative to AODV, OLSR and GPSR that can exploit some of the more characteristics unique to VANETS.
TABLE II

DROP RATIO ON BOTH MAC AND NETWORK LAYERS

\begin{tabular}{|c|c|c|c|c|c|c|}
\hline \multirow{2}{*}{$\begin{array}{l}\text { AODV } \\
\text { Load }\end{array}$} & \multicolumn{2}{|c|}{$\begin{array}{c}\text { Manhattan } \\
\text { Dropped }\end{array}$} & \multicolumn{2}{|c|}{$\begin{array}{c}\text { Czone } \\
\text { Dropped }\end{array}$} & \multicolumn{2}{|c|}{$\begin{array}{c}\text { Leicester } \\
\text { Dropped }\end{array}$} \\
\hline & NR & MAC & NR & MAC & NR & MAC \\
\hline 200 & 0.67 & 0.33 & 0.68 & 0.31 & 0.68 & 0.32 \\
\hline 400 & 0.77 & 0.22 & 0.78 & 0.21 & 0.78 & 0.21 \\
\hline 600 & 0.81 & 0.18 & 0.82 & 0.17 & 0.82 & 0.17 \\
\hline 800 & 0.84 & 0.15 & 0.84 & 0.15 & 0.84 & 0.15 \\
\hline 1000 & 0.85 & 0.13 & 0.86 & 0.13 & 0.86 & 0.13 \\
\hline OLSR & \multicolumn{2}{|c|}{$\begin{array}{c}\text { Manhattan } \\
\text { Dropped }\end{array}$} & \multicolumn{2}{|c|}{$\begin{array}{c}\text { Czone } \\
\text { Dropped }\end{array}$} & \multicolumn{2}{|c|}{$\begin{array}{l}\text { Leicester } \\
\text { Dropped }\end{array}$} \\
\hline Load & NR & MAC & NR & MAC & NR & MAC \\
\hline 200 & 0.13 & 0.86 & 0.15 & 0.85 & 0.15 & 0.85 \\
\hline 400 & 0.25 & 0.75 & 0.20 & 0.80 & 0.17 & 82 \\
\hline 600 & 0.39 & 0.61 & 0.34 & 0.66 & 0.32 & 0.67 \\
\hline 800 & 0.49 & 0.51 & 0.44 & 0.55 & 0.44 & 0.56 \\
\hline 1000 & 0.57 & 0.43 & 0.53 & 0.47 & 0.52 & 0.48 \\
\hline GPSR & \multicolumn{2}{|c|}{$\begin{array}{c}\text { Manhattan } \\
\text { Dropped }\end{array}$} & \multicolumn{2}{|c|}{$\begin{array}{c}\text { Czone } \\
\text { Dropped }\end{array}$} & \multicolumn{2}{|c|}{$\begin{array}{l}\text { Leicester } \\
\text { Dropped }\end{array}$} \\
\hline Load & NR & MAC & NR & MAC & NR & MAC \\
\hline 200 & 0.62 & 0.37 & 0.45 & 0.55 & 0.49 & 0.51 \\
\hline 400 & 0.44 & 0.56 & 0.32 & 0.68 & 0.38 & 0.62 \\
\hline 600 & 0.34 & 0.66 & 0.27 & 0.73 & 0.31 & 0.69 \\
\hline 800 & 0.32 & 0.68 & 0.22 & 0.77 & 0.25 & 0.75 \\
\hline 1000 & 0.28 & 0.71 & 0.20 & 0.80 & 0.22 & 0.78 \\
\hline
\end{tabular}

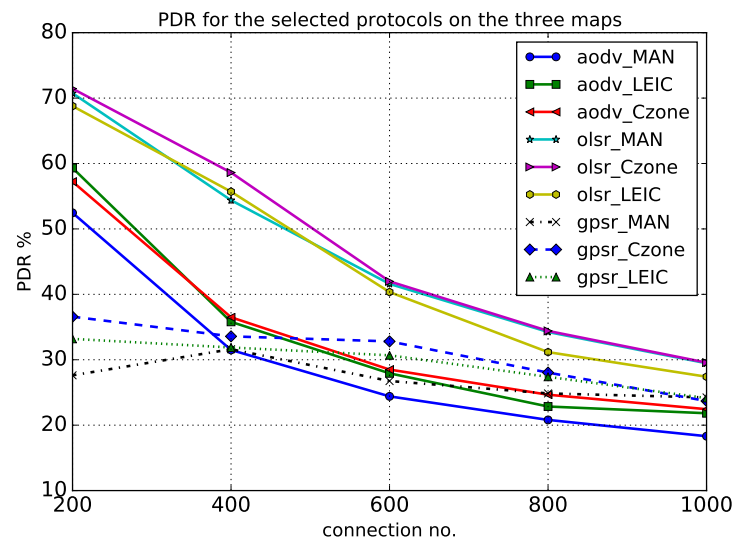

Fig. 7. Packet Delivery Ratio (PDR) of the selected protocols on the all maps.

\section{ACKNOWLEDGMENT}

This work was completed while $\mathrm{Mr}$ Ali was a graduate student at Loughborough University, UK. The authors thank Iraqi MOHESR for financial support.

\section{REFERENCES}

[1] S. Zeadally, R. Hunt, Y.-S. Chen, A. Irwin, and A. Hassan, "Vehicular ad hoc networks (VANETS): status, results, and challenges," Telecommun. Syst., vol. 50, no. 4, pp. 217-241, dec 2010.

[2] F. Cunha, L. Villas, A. Boukerche, G. Maia, A. Viana, R. A. F. Mini, and A. A. F. Loureiro, "Data Communication in VANETs: Survey, Applications and Challenges," Ad Hoc Networks, pp. 1-12, 2016.

[3] C. Perkins and E. Royer, "Ad-hoc on-demand distance vector routing," in Proc. WMCSA'99. Second IEEE Work. Mob. Comput. Syst. Appl., no. 3, 2009, pp. 90-100.

[4] P. Jacquet, P. Muhlethaler, T. Clausen, A. Laouiti, A. Qayyum, and L. Viennot, "Optimized link state routing protocol for ad hoc networks," in Proceedings. IEEE International Multi Topic Conference, 2001. IEEE INMIC 2001. Technology for the 21st Century., 2001, pp. 62-68. 

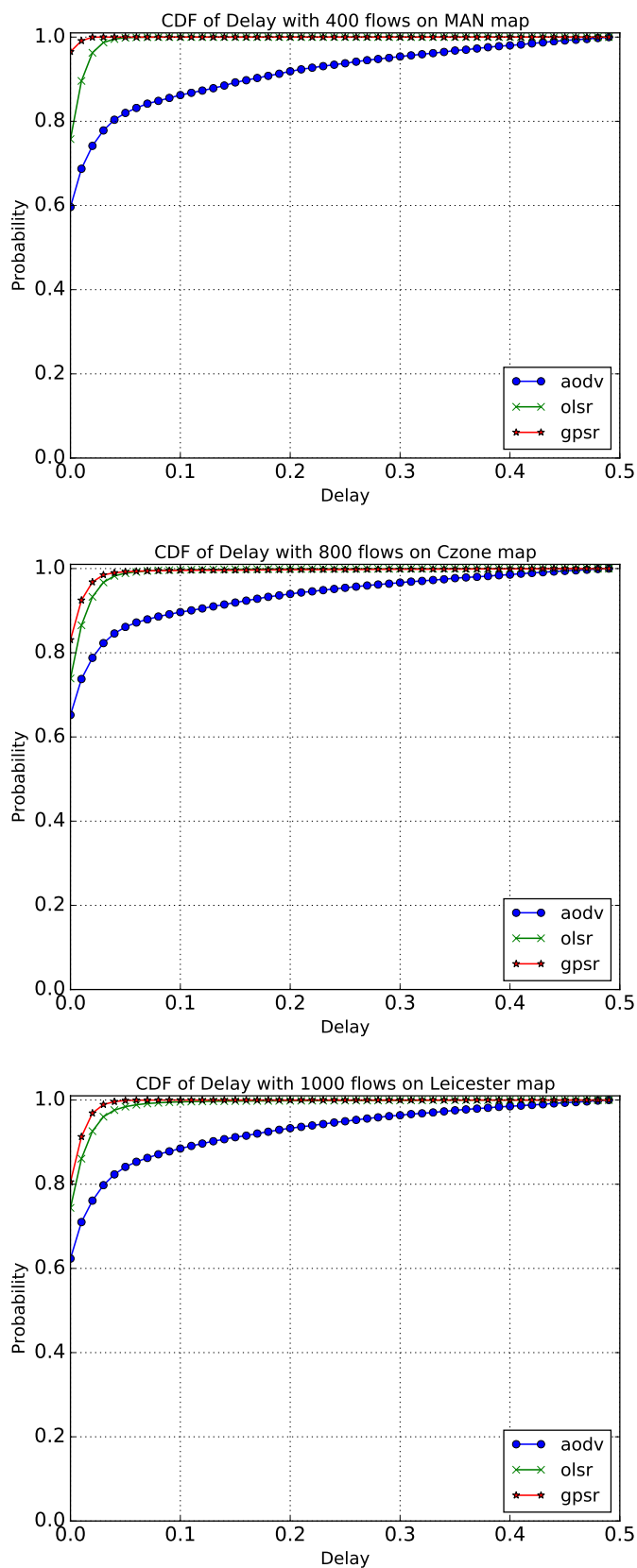

Fig. 8. CDF of delay for the selected protocols under various network loads.

[5] B. Karp and H. T. Kung, "Gpsr," Proc. 6th Annu. Int. Conf. Mob. Comput. Netw. - MobiCom '00, pp. 243-254, 2000.

[6] P. Rani, N. Sharma, and P. K. Singh, "Performance comparison of VANET routing protocols," in 7 th Int. Conf. Wirel. Commun. Netw. Mob. Comput. WiCOM 2011, 2011, pp. 1-4.

[7] J. Zuo, Y. Wang, Y. Liu, and Y. Zhang, "Performance evaluation of routing protocol in VANET with vehicle-node density," in 2010 6th Int. Conf. Wirel. Commun. Netw. Mob. Comput. WiCOM, 2010.

[8] I. Khan and A. Qayyum, "Performance evaluation of AODV and OLSR in highly fading Vehicular Ad hoc Network environments," in INMIC 2009 - 2009 IEEE 13th Int. Multitopic Conf., 2009, pp. 1-5.

[9] R. Bala and C. R. Krishna, "Scenario based performance analysis of AODV and GPSR routing protocols in a VANET," Proc. - 2015 IEEE Int. Conf. Comput. Intell. Commun. Technol. CICT 2015, pp. 432-437, 2015.

[10] E. Spaho, M. Ikeda, L. Barolli, and F. Xhafa, "Performance comparison of OLSR and AODV protocols in a VANET crossroad scenario," Lect. Notes Electr. Eng., vol. 253 LNEE, pp. 37-45, 2013.
[11] E. Spaho, L. Barolli, G. Mino, F. Xhafa, V. Kolici, and R. Miho, "Performance Evaluation of AODV, OLSR and DYMO Protocols for Vehicular Networks Using CAVENET," in 2010 13th Int. Conf. NetworkBased Inf. Syst., 2010, pp. 527-534.

[12] C. Haerri, J. and Filali, F. and Bonnet, "Performance comparison of AODV and OLSR in VANETs urban environments under realistic mobility patterns," in Proc. 5th IFIP Mediterr. Ad-Hoc Netw. Work., no. i, 2006, pp. 14-17.

[13] A. K. Ali, I. Phillips, and H. Yang, "Evaluating VANET Routing in Urban Environments," 39th Int. Conf. Telecommun. Signal Process., pp. 60-63, 2016.

[14] Crash Avoidance Metrics Partnership. Vehicle Safety Communications Consortium, Vehicle Safety Communications Project: Task 3 Final Report : Identify Intelligent Vehicle Safety Applications Enabled by DSRC. National Highway Traffic Safety Administration, 2004.

[15] M. Behrisch, L. Bieker, J. Erdmann, and D. Krajzewicz, "SUMO Simulation of Urban MObility - an Overview," Proc. 3rd Int. Conf. Adv. Syst. Simul., no. c, pp. 63-68, 2011.

[16] F. Bai, N. Sadagopan, and A. Helmy, "The IMPORTANT framework for analyzing the impact of mobility on performance of RouTing protocols for Adhoc NeTworks," Ad Hoc Networks, vol. 1, no. 4, pp. 383-403, 2003.

[17] M. Nakagami, "The m-distribution - A General Formula of Intensity Distribution of Rapid Fading," Stat. Methods Radio Wave Propag., pp. 3-36, 1960 .

[18] L. Rubio, J. Reig, V. M. Rodrigo-Pearrocha, and N. Cardona, "A semi-deterministic propagation model for predicting short-term fading statistics in urban environments based on the Nakagami-m distribution," AEU - Int. J. Electron. Commun., vol. 61, no. 9, pp. 595-604, 2007.

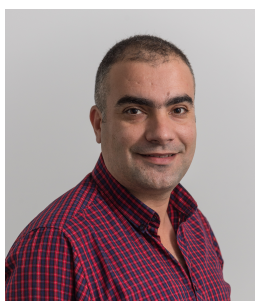

Awos Kh. Ali is a Ph.D. research student in Computer Science at University of Loughborough, UK. His research focuses on computer networks and routing algorithms. He received his B.Sc. degrees in Computer Science from the University of Mosul, IRAQ in 2003 and his Masters degrees in Computer Science and Information Technology from the University of Technology (UTM), Malaysia in 2008

Since 2009 he has worked at Mosul University, IRAQ, as a Lecturer.

Iain Phillips is a Senior Lecturer in Comptuer Science, specialising in computer networking including monitoring and measuring performance. He received Ph.D. (Computer Science Parallel Computing) and B.Sc. degrees (Computing and Information Systems) from the University of Manchester, UK and been involved in distributed systems research for over 25 years.

Since 1992 he has worked at Loughborough University, UK, as a Research Associate, then Research Fellow, Lecturer and Senior Lecturer. From 2008-11 and from 2016 onwards he served as Head of the Department of Computer Science. During 2011-12 he took a sabbatical year spending time at the University of Cambridge, UK and the University of Adelaide, Australia. He has over 100 publications in this Computer Networking and Distributed Computing. from 2012-14 he was Chair of the Council of Professors and Heads of Computing (CPHC), UK.

Dr Phillips is a Chartered Engineer, Chartered IT Professional, Fellow of the British Computer Society, Fellow of the Higher Education Academy and Member of the ACM. He has reviewed for many journals and is on the Editorial Board of IET Networks.

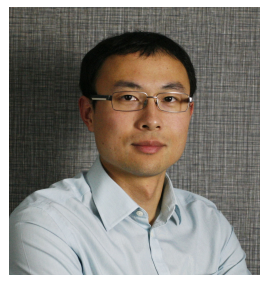

Huanjia Yang received his BSc in 2004 in Informaion and Telecommunication Engineering from Xi'an Jiaotong University in China, and in 2006 an MSc (Diplme d'Ingnieur) in Information and Communication Systems from the University of Technology, Troyes, in France. He got a PhD in Computer Science in 2010 from Loughborough University in UK. He is now a Senior Application Developer and the Manager of Application Development Sector at IBM Client Innovation Centre in Leicester, UK. His research interests include routing, identification and location tracking in Wireless Sensor Networks, Internet/Web of Things and Enterprise Information System. 